\title{
In focus in $\mathrm{HCB}$
}

\section{Douglas J. Taatjes ${ }^{1}$ Jürgen Roth ${ }^{2}$}

Published online: 30 June 2020

○) Springer-Verlag GmbH Germany, part of Springer Nature 2020

We welcome our readers to the July issue of Histochemistry and Cell Biology, and hope that you are remaining safe and well as the world begins phased reopenings. In this Editorial, we highlight one Review detailing information on the effects of Hematoxylin and Eosin and Papanicolaou staining on nucleic acid integrity for downstream molecular investigations, and three Original Articles providing insights into (1) the histogenesis of adenosquamous carcinoma of the pancreas; (2) the localization, proliferation, and phenotype of human palatine tonsil plasma cells in germinal centers; and (3) the combination of conventional histochemical staining methods for the simultaneous visualization of mast cells and different stages of fibrillogenesis in the dermis of rat skin.

\section{Influence of H\&E and Pap stains on nucleic acid integrity}

Application of hematoxylin and eosin (H\&E) dyes is the standard contrast enhancement method for the optimal conventional light microscopic visualization of cells and tissue components in both formalin-fixed paraffin-embedded (FFPE) and frozen (cryostat) sections (Carson 1997). Likewise, for contrast enhancement of cell smears, the Papanicolaou (Pap) stain has become the laboratory standard (Papanicolaou 1942). Oftentimes, molecular signatures of cells relayed through DNA and RNA sequences are sought from fixed, processed, and stained samples. In this regard, Pote et al. (2020) have provided a thorough review of the literature concerning the effects of H\&E and Pap staining on subsequent nucleic acid analysis through techniques such as PCR. They provide details on the likely chemical

Douglas J. Taatjes

douglas.taatjes@med.uvm.edu

1 Department of Pathology and Laboratory Medicine, Larner College of Medicine, University of Vermont, Burlington, VT 05405, USA

2 University of Zurich, 8091 Zurich, Switzerland interactions occurring between these dyes and nuclear and cytoplasmic components of the cell. Although all of the literature was not necessarily in agreement, generally speaking, the take home message was H\&E or Pap staining of samples resulted in lower DNA recovery and some DNA fragmentation in comparison to unstained samples. The suggestion for RNA analysis was to use frozen sections, and vigilantly maintain RNAse-free conditions, although more data are required for the effects of processing and staining on these nucleic acids. The authors also provide three extensive summary tables from the literature which can be referred to for further details. In summary, this timely review should be referred to for those planning to perform molecular nucleic acid analyses from stained tissue and cell samples.

\section{Model for the histogenesis of adenosquamous carcinoma of the pancreas}

Adenosquamous carcinomas can occur in multiple tissue types, yet the mechanism(s) responsible for their histiogenesis is not clear. In the pancreas, adenosquamous carcinoma (ASCAP) presents as a rare histological subtype of pancreatic ductal adenocarcinoma (PDAC) (Kardon et al. 2001), consisting of portions of both squamous and glandular carcinoma components. Several models have been proposed for the formation of ASCAP: (1) the "differentiation" theory, whereby the squamous and adenocarcinoma components develop from identical progenitor cancer cells; (2) the "squamous metaplasia" theory positing that the malignant squamous component of ASCAP originates from pre-existing PDAC; and (3) the "collision" theory proposing that the glandular and squamous components originate independently and merge to form one tumor. To test the validity of these theories, Boecker et al. (2020) have performed histological and multiple-label immunohistochemical analyses on a series of 25 cases diagnosed as ASCAP and 20 cases diagnosed as PDAC. The immunostaining was performed 

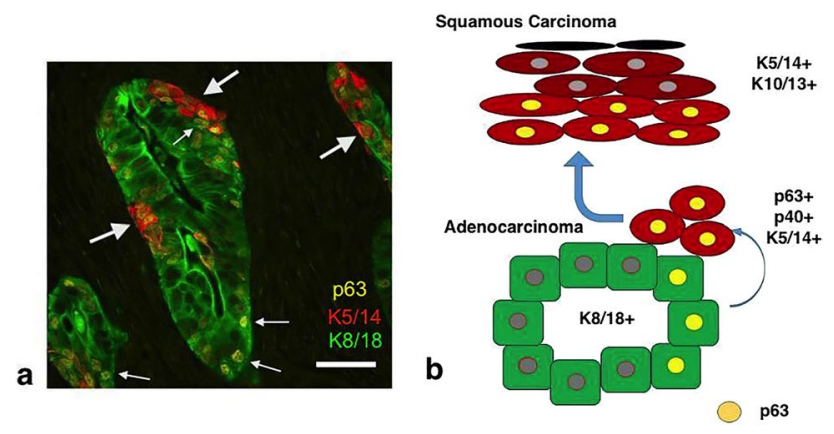

Fig. 1 Hypothetical model of histogenesis of adenosquamous carcinoma of the pancreas. a Triple immunofluorescence demonstrating the expression of p63 in the $\mathrm{k} 8 / 18+$ glandular cells (small arrows) and the basally located p63+K5/14+ cells (large arrows). b Hypothetical cellular model explaining the development of the glandular and squamous components in these tumors. From Boecker et al. (2020)

with antibodies recognizing multiple keratin isotypes, p63, p40, CEA, EGFR, MUC1, MUC2, MUC5AC, p53, and Ki67. They present beautiful images of H\&E histology, singly stained immunoperoxidase sections, and triple stained immunofluorescence (Fig. 1).

Their results demonstrate that most ASCAPs contain a "transitional zone" located between the K8/18(+)/ MUC5AC(+) adenocarcinomatous cells and the p63(+)/ $\mathrm{p} 40(+) / \mathrm{K} 5 / 14(+)$ squamous cells. Moreover, this transition zone is also characterized by the initial appearance of nuclear p63 in $\mathrm{K} 8 / 18(+)$ glandular cells together with the appearance of p63(+)/K5/14(+) cells in a basal location. These cells likely proliferate and differentiate to ultimately form the squamous cell component of ASCAP. Thus, their results support the "squamous metaplasia" theory of ASCAP formation by providing strong evidence suggesting that the squamous carcinoma component originates from a pre-existing K8/18(+) PDAC via transdifferentiation of glandular cells to $\mathrm{p} 63(+) / \mathrm{p} 40(+) / \mathrm{K} 5 / 14(+)$ squamous carcinoma cells.

\section{Immunohistochemical characterization of tonsillar plasma cells inside and outside of germinal centers}

The human palatine tonsil contains many secondary follicles which may have active germinal centers (Curran and Jones 1977; Korsrud and Brandtzaeg 1980). Steiniger et al. (2020) have revisited models of germinal center function in regard to plasma cell location, phenotype and proliferation by applying multiple labeling immunohistochemistry for the detection of CD38, CD138, CD27, and IRF4, and intracellular (ic) $\operatorname{IgM}, \operatorname{IgD}, \operatorname{IgG}$ and $\operatorname{Ig} \mathrm{A}$. Germinal center

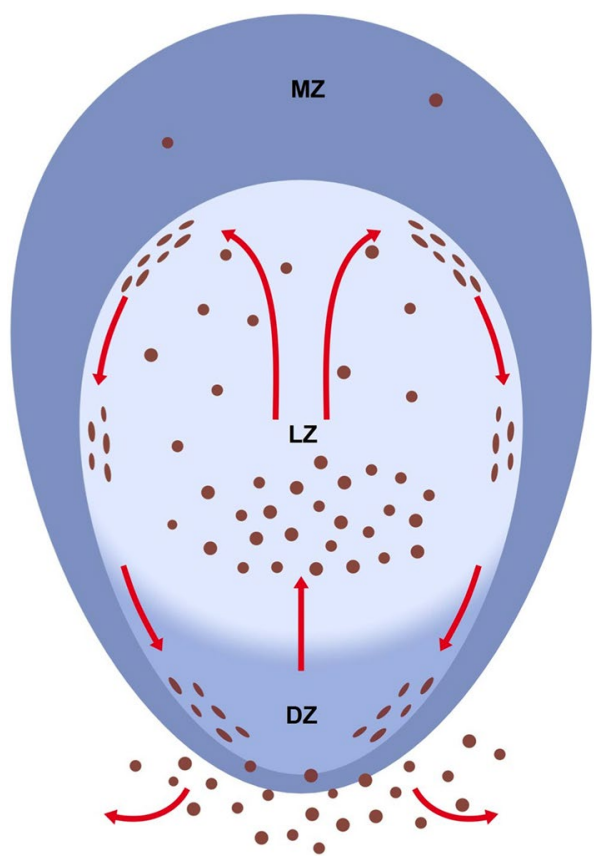

Fig. 2 Hypothetical migration route of $\mathrm{CD} 8^{++} \mathrm{icIg}^{+}$plasma cells (brown) in tonsil germinal centers. $M Z$ mantle zone, $L Z$ light zone, $D Z$ dark zone. From Steiniger et al. (2020)

plasma cells positive for these antigens often accumulated in the basal light zone and were also observed at the germinal center surface to the mantle zone. Surprisingly, the majority of the strongly CD38 and/or CD138 or (ic)Igs-positive cells were unreactive for $\mathrm{Ki}-67$, indicating that they represented mature plasma cells and not plasmablasts. Cells with such an immunohistochemical phenotype were also detected in germinal centers of spleen and lymph nodes. In regard to plasma cells of tonsillar germinal centers, the authors speculate that those at the germinal center surface may be either destined for immediate emigration via the superficial dark zone or may be actively contacting the most superficial follicular dendritic cells for some time (Fig. 2).

Furthermore, plasma cells with different Ig isotype showed a characteristic distribution pattern. Those with (ic)IgM positivity were rarely found outside the germinal centers, while (ic) IgA and (ic)IgG-positive plasma cells were most often found in intra- and subepithelial regions. Additional immunohistochemical analysis indicated that the surface of the dark zone may also be an exit site for $\mathrm{Ki}-67^{+} \mathrm{CD} 30^{+} \mathrm{B}$ lymphoblasts, which seed perifollicular and extrafollicular sites. Thus, the authors hypothesize that the germinal centers are a major source of plasma cells and $\mathrm{CD} 30^{+} \mathrm{B}$ lymphoblasts. They also mention the possibility that some plasma cells may become permanent residents of the germinal center. 


\section{Mast cells and fibrillogenesis in the skin dermis-a histochemical approach}

Mast cells belong to the mobile connective tissue cells and may constitute organ-specific populations (Atiakshin et al. 2017; Frossi et al. 2018). They contain many large secretory granules (Pavelka and Roth 2015) storing mainly histamine, heparin, proteoglycans and proteases such as tryptase and chymase, which are released upon activation. Mast cells play a crucial role in the defense system and are also involved in various pathologic immune reactions (Galli and Tsai 2008; Olivera et al. 2018). In addition, they are involved in the remodeling of the connective tissue matrix and induction of fibrillogenesis (Atiakshin et al. 2018, 2019; Conti et al. 2018; Overed-Sayer et al. 2014). Atiakshin et al. (2020) have evaluated 20 combinations of conventional histochemical staining methods to investigate their usefulness for the simultaneous visualization of mast cells and different stages of fibrillogenesis in the dermis of the skin. As revealed by an exceedingly detailed analysis, best results were obtained using metachromatic detection of mast cells with toluidine blue in combination with silver or picro-fuchsin impregnation, or staining with brilliant green using van Gieson's staining, and a combination of aniline blue staining with neutral red (Fig. 3).

The authors point out that silver impregnation permitted the analysis of initial stages of fibrillogenesis in the dermis. A main conclusion drawn by the authors is that the reported combination staining methods for mast cells and the fibrillar tissue matrix component represent easy and practicable methods to study fibrillogenesis in a tissue microenvironment with cellular component participation suitable for the

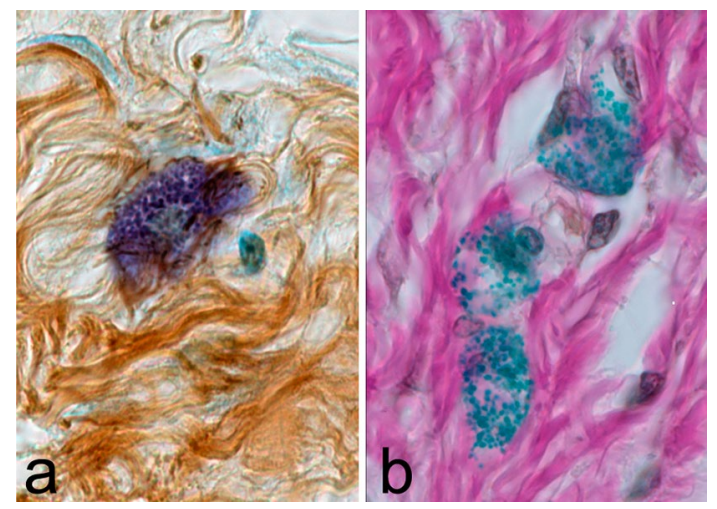

Fig. 3 a Combination of toluidine blue staining for mast cells and silver impregnation for the fibrous component in normal rat skin. b Combination of brilliant green for mast cells and van Gieson's stain for the fibrous component in rat skin 7 days after injury. From Atiakshin et al. (2020) assessment of adaptive processes and the diagnosis of pathological conditions.

\section{References}

Atiakshin D, Samoilova V, Buchwalow I, Boecker W, Tiemann M (2017) Characterization of mast cell populations using different methods for their identification. Histochem Cell Biol 147:683-694

Atiakshin D, Buchwalow I, Samoilova V, Tiemann M (2018) Tryptase as a polyfunctional component of mast cells. Histochem Cell Biol 149:461-477

Atiakshin D, Buchwalow I, Tiemann M (2019) Mast cell chymase: morphofunctional characteristics. Histochem Cell Biol 152:253-269

Atiakshin D, Buchwalow I, Tiemann M (2020) Mast cells and collagen fibrillogenesis. Histochem Cell Biol. https://doi.org/10.1007/ s00418-020-01875-9

Boecker W, Tiemann K, Boecker J, Toma M, Muders MH, Löning T, Buchwalow I, Oldhafer KJ, Neumann U, Feyerabend B, Fehr A, Stenman G (2020) Cellular organization and histogenesis of adenosquamous carcinoma of the pancreas: evidence supporting the squamous metaplasia concept. Histochem Cell Biol. https:// doi.org/10.1007/s00418-020-01864-y

Carson FL (1997) Histotechnology—a self-instructional text. ASCP Press, Chicago

Conti P, Caraffa A, Mastrangelo F, Tettamanti L, Ronconi G, Frydas I, Kritas SK, Theoharides TC (2018) Critical role of inflammatory mast cell in fibrosis: potential therapeutic effect of IL-37. Cell Prolif 51:e12475

Curran RC, Jones EL (1977) Immunoglobulin-containing cells in human tonsils as demonstrated by immunohistochemistry. Clin Exp Immunol 28:103-115

Frossi B, Mion F, Sibilano R, Danelli L, Pucillo CEM (2018) Is it time for a new classification of mast cells? What do we know about mast cell heterogeneity? Immunol Rev 282:35-46

Galli SJ, Tsai M (2008) Mast cells: versatile regulators of inflammation, tissue remodeling, host defense and homeostasis. J Dermatol Sci 49:7-19

Kardon DE, Thompson LD, Przygodzki RM, Heffess CS (2001) Adenosquamous carcinoma of the pancreas: a clinicopathologic series of 25 cases. Mod Pathol 14:443-451

Korsrud FR, Brandtzaeg P (1980) Immune systems of human nasopharyngeal and palatine tonsils: histomorphometry of lymphoid components and quantification of immunoglobulin-producing cells in health and disease. Clin Exp Immunol 39:361-370

Olivera A, Beaven MA, Metcalfe DD (2018) Mast cells signal their importance in health and disease. J Allergy Clin Immunol 142:381-393

Overed-Sayer C, Rapley L, Mustelin T, Clarke DL (2014) Are mast cells instrumental for fibrotic diseases? Front Pharmacol 4:174. https:// doi.org/10.3389/fphar.2013.00174

Papanicolaou GN (1942) A new procedure for staining vaginal smears. Science 95:438-439

Pavelka M, Roth J (2015) Functional ultrastructure. Atlas of tissue biology and pathology, 3rd edn. Springer, Vienna

Pote A, Boghenco O, Marques-Ramos A (2020) Molecular analysis of H\&E- and Papanicolau-stained samples - systematic review. Histochem Cell Biol. https://doi.org/10.1007/s00418-020-01882-w

Steiniger BS, Raimer L, Ecke A et al (2020) Plasma cells, plasmablasts, and $\mathrm{AID}^{+} / \mathrm{CD} 30^{+} \mathrm{B}$ lymphoblasts inside and outside germinal centres: details of the basal light zone and the outer zone in human palatine tonsils. Histochem Cell Biol. https://doi.org/10.1007/s0041 8-020-01861-1 


\section{News from the Society for Histochemistry}

\section{$16^{\text {TH }}$ INTERNATIONAL CONGRESS OF HISTOCHEMISTRY AND CYTOCHEMISTRY}

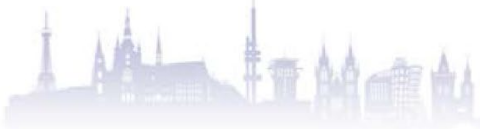

5 - 8 September

PRAGUE
Dear Colleagues,

In the light of the COVID-19 pandemic, the ICHC 2020 organizers and IFSHC Executive Council decided to postpone the ICHC 2020 to 5 - 8 September 2021. The ICHC 2021 will take place as originally planned in the Cubex Centre, Prague, Czech Republic. The safety of all participants is our top priority. We are sorry for any inconvenience the postponement might have caused you.

The ICHC is held every four years under the auspices of the International Federation of Societies for Histochemistry and Cytochemistry (IFSHC), which continually strives to provide grounds for communication and cooperation among scientists all over the world in the areas of cyto- and histochemistry, cell and tissue biology, microscopy, pathology and other relevant fields.

The city of Prague, also known as the heart of Europe, provides easy access for scientists from all over the world. The congress venue, Cubex Centre Prague which offers technologically and visually unique space, promises to leave everyone with an unforgettable experience. Of course, Prague prides itself with its beautiful historical architecture, technical monuments, celebrated cafés, great food, and beer. This will be underlined by the ICHC gala dinner in the famous Art Nouveau Municipal House, and a free beer party organized in the premises of the Staropramen brewery.

We hope that you will join us in Prague to discuss together your latest achievements and that the venue will provide great opportunities for specialists at all levels of their career, bringing lots of opportunities for strengthening international collaborations. Special attention will be therefore given to the presentations of students. We also expect a rich commercial exhibition where new and emerging technologies will be presented.
We are delighted to inform you that the following speakers will present a lecture at the congress:

Stefan Hell, a Nobel Prize laureate, Max Planck Institute for Biophysical Chemistry, Germany (keynote speaker)

Alev Erisir, Department of Psychology, University of Virginia, USA

Toyoshi Fujimoto, Juntendo University, Nagoya, Japan

Hans-Joachim Gabius, Institute of Physiological Chemistry, Ludwig Maximilians University of Munich, Germany

Bozena Kamińska, Nencki Institute of Experimental Biology PAS Warszawa, Poland Takehiko Koji, Department of Histology and Cell Biology, Nagasaki University Graduate School of Biomedical Sciences, Nagasaki, Japan Ohad Medalia, Department of Biochemistry, University of Zurich, Switzerland

See you all in Prague, September 2021!

Hinke Multhaupt, President of the IFSHC

Klara Weipoltshammer, President of the Society for Histochemistry

Pavel Hozak, Chair of the Local Organizing Committee

\section{Contacts}

We will keep the current domain: www.ichc2020.com

If you have any questions about registration, please contact: registration@ichc2020.com

If you have any questions about abstracts, please contact: abstracts@ichc2020.com

Other inquiries and comments about the conference, please contact: info@,ichc2020.com 


\section{ANNOUNCEMENT}

\section{The Society for Histochemistry}

Invites scientists to apply for the 2021

Robert Feulgen Prize. The prize is awarded for an outstanding achievement in the field of histochemistry.

The contributions may be either towards the development of new histochemical and cytochemical techniques or in the application of existing technology towards solving important problems in biology and/or medicine. Addressed are scientists working in microscopical sciences (in the widest sense) as well as in biochemistry, cell biology, endocrinology, in situ molecular techniques, and neurosciences. Scientists in their mid-career (assistant or associate professor, priv. doz.) are encouraged to apply. The prize is not intended for lifetime contributions.

The Prize consists of a monetary prize of $€ 2,000$

All applications should be submitted before January 31, 2021 via the electronic submission system at: https://www.greception.com/form-login-window/ 191a281d/

The application should contain a short curriculum vitae, a 1,000 word summary of the contributions of the applicant and PDF reprints of the pertinent publications. Full description of conditions is available on the Society website: http://histochemistry.eu/ description_of_conditions_html

Publisher's Note Springer Nature remains neutral with regard to jurisdictional claims in published maps and institutional affiliations. 